\title{
Criteria for appointment to observer and examination panels and overseas examinations
}

\author{
Stephen P. Tyrer
}

The procedure for nomination to the MRCPsych Board of Examiners was recently published in Psychiatric Bulletin (Tyrer, 1999). These have led to enquiry by Members and Fellows of the College about the criteria for appointment to other Committees and Panels that are under the aegis of the Examinations Department. Following discussion at the Examinations Sub-Committee the criteria for appointment of psychiatrists to the Panel of Observers, the Panels concerned with the development of questions for the Multiple Choice Papers in both Parts of the MRCPsych Examinations, the Critical Review Paper and the Essay Paper in Part II of the Examination and for Overseas Examiners, are indicated below.

\section{Criteria for appointment to the Panel of Observers}

Observers of the MRCPsych Examinations should:

(a) Have a good knowledge of Examination procedure through previous appointment as a Senior Organiser, Examiner or Membership of an Examinations Panel or SubCommittee.

(b) Be willing and available to observe on a regular basis.

(c) Be willing to travel to any clinical centre in UK or Ireland.

(d) Be willing to provide feedback to unsuccessful candidates.

(e) $\mathrm{Be}$ avallable to attend Annual General Meetings and Panel of Observers meetings to maintain knowledge of developments in the MRCPsych Examinations.

(f) Be willing to examine at a clinical centre when an examiner is not available (but only if registered with Continuing Professional Development). Members will normally be registered for Continuing Professional Development at the time of appointment.
Membership of the Panel of Observers is for five years, but is renewable for a further five years on the decision of the Examinations SubCommittee.

\section{Criteria for appointment to examination panels}

Aspirants for appointment to the MRCPsych Examination Panels should have:

(a) A wide knowledge of an aspect of clinical psychiatry or related speciality or interest.

(b) A commitment to attend Panel meetings regularly.

(c) A commitment to write new Examination questions on a regular basis and validate existing questions.

(d) A commitment to membership of the Panel for three years.

\section{Criteria for appointment as a nominated College Examiner overseas}

The criteria for nominees examining abroad are as follows:

(a) Recent or prior experience of examining in the MRCPsych Examinations.

(b) Familiarity with the format and performance of recent professional psychiatric examinations.

(c) An undertaking to give feedback on the overseas Examination if requested.

\section{Reference}

TYRER, S. P. (1999) Procedure for the nomination of examiners. Psychiatric Bulletin, 23, 251-252.

Stephen P. Tyrer, Chief Examiner, Royal College of Psychiatrists, 17 Belgrave Square, London SWIX 8PG 